\title{
Team Innovation Climate and Knowledge Sharing among Healthcare Managers: Mediating Effects of Altruistic Intentions
}

\author{
Feng-Chuan Liu, PhD; Kai-Lin Cheng ${ }^{2}$, HMA; Minston Chao' ${ }^{1}$ PhD; Hsu-Min Tseng ${ }^{1}, \mathrm{PhD}$
}

Background: This paper aims to provide empirical evidence concerning the impact of team climate on knowledge sharing behavior and the mediating effects of individuals' altruistic intentions in the context of healthcare settings.

Methods: Questionnaire data were collected from 212 administrators employed at a medical center in Taiwan. Team climate was assessed by the Team Climate Inventory composed of four factors, participative safety, support for innovation, vision, and task orientation. The proposed hypotheses were tested using structural equation modeling.

Results: The influence of the team innovation climate on knowledge sharing behavior was evident. Furthermore, individuals' altruistic intentions played a full mediating role in the relationship between team innovation climate and knowledge sharing behavior.

Conclusions: These results contribute to the field of the people-orientated perspective in knowledge management. The full mediating effect of employees' altruistic intentions provides healthcare team managers the direction to accelerate knowledge sharing behavior.

(Chang Gung Med J 2012;35:408-19)

Key words: knowledge sharing, team innovation climate, altruistic intention, healthcare management

\begin{abstract}
$\mathrm{A}^{\mathrm{s}}$ $\mathrm{s}$ knowledge assets are what permit healthcare organizations to achieve better results than their competitors, there has been a growing interest in communities of practice as a means of transferring and generating knowledge within a healthcare organization. ${ }^{(1-4)}$ Increasingly, healthcare organizations are attempting to set up knowledge management systems and practices to more effectively use the knowledge they have. Nevertheless, the translation of knowledge management into practice is a well-recognized challenge for the health sector. Knowledge manage-
\end{abstract}

ment implies a series of policies and guidelines that enable creating, diffusing and institutionalizing knowledge to achieve the firm's objectives. ${ }^{(5)}$ Although information technology-driven perspectives have traditionally dominated the field of knowledge management, there is increasing recognition of the individual role in knowledge management processes and a growing interest in the "people perspective' of knowledge management in organizations. ${ }^{(6)}$

The key for successful knowledge management

From the Graduate Institute of Business and Management; 'Department of Health Care Management, Chang Gung University, Taoyuan, Taiwan; ${ }^{2}$ Cardinal Tien Hospital, Taipei, Taiwan.

Received: Jan. 14, 2011; Accepted: Apr. 11, 2012

Correspondence: Assoc. Prof. Hsu-Min Tseng, Department of Healthcare Management, Chang Gung University. 259, Wunhua 1st Rd., Gueishan Township, Taoyuan County 333, Taiwan (R.O.C.) Tel: 886-3-2118800 ext. 5434; Fax: 886-3-2118345;

E-mail: tsenghm@mail.cgu.edu.tw 
depends on the connections among individuals within an organization, because knowledge resides within individuals. ${ }^{(7,8)}$ The movement of knowledge across individuals and organizational units is ultimately dependent upon employees' knowledge sharing behaviors. Organizations depend on employees' knowledge sharing behavior to increase their competitive advantage and value. ${ }^{(9)}$ Therefore, knowledge sharing has become one of the important strategies used for knowledge management. ${ }^{(10)}$ In practice, the lack of knowledge sharing has proven to be one of the major barriers to effective knowledge management. ${ }^{(11-13)}$ More specifically, sharing employees' skills and expertise is likely to enhance organizational capabilities in knowledge management and renewal, and consequently to produce more-than-desirable work outcomes. Given the importance of knowledge sharing behavior, scholars and practitioners are interesting in identifying factors that enhance knowledge sharing behaviors within an organization. This study attempts to verify whether an innovative team climate stimulates individuals' altruistic tendencies in a healthcare organization, and consequently enhances knowledge sharing behaviors.

Knowledge management has been defined as the process designed to help organizations create, capture, analyze, apply, and reuse knowledge to achieve competitive advantage. ${ }^{(14)}$ More specific to this study, knowledge sharing concerns the willingness of individuals within a team to share with others the knowledge they have acquired. ${ }^{(9)}$ Through the sharing process, employees can acquire valuable knowledge to increase their performance. Choi and his colleagues suggested that knowledge sharing is a multidimensional activity and thus involves several contextual, cognitive, and communicative skills. ${ }^{(15)}$ There are enablers that facilitate knowledge sharing behaviors from two perspectives, i.e. the technical versus the people-oriented perspective.

The emphasis of the technical perspective is on providing guidelines for implementing knowledge systems. In contrast, the people-oriented perspective focuses upon motivational or contextual factors that are likely to motivate or induce knowledge sharing behaviors. A number of studies have examined various motivational factors that influence knowledge sharing intentions or behaviors in organizational settings, such as positive attitudes toward knowledge sharing, ${ }^{(16)}$ and extrinsic rewards, ${ }^{(17)}$ as well as intrin- sic motivations such as altruistic concerns for others and self-interest. ${ }^{(18,19)}$ In addition to individuals' motivation, studies have attempted to identify work environments and social climates that play a significant role in shaping attitudes toward knowledge sharing in a working setting. ${ }^{(9)}$

The aim of this study was to examine how and why healthcare managers participate in collaborative knowledge sharing in the context of healthcare settings. This study attempts to verify whether an innovative team climate stimulates individuals' altruistic tendencies in a healthcare organization, and consequently enhances knowledge sharing behaviors. We aim to provide an empirical model that helps healthcare managers in the important task of identifying factors that facilitate employees' knowledge-sharing behaviors. Employing the theory of planned behavior ${ }^{(20)}$ we tested a research model to explore the theoretical intersections between intrinsic motivation (i.e. altruism) and contextual factors (i.e. team climate) pertaining to knowledge-sharing behaviors.

\section{Intrinsic motivation: altruistic intention}

An organization's ability to leverage its knowledge effectively is highly dependent on the willingness of its members to share knowledge, because organizational knowledge largely resides within an individual. As Von Krogh states, the lack of willingness to share knowledge is one of the fundamental problems faced by organizations in the transaction process. ${ }^{(21)}$ De Vries et al. pointed out that willingness to share knowledge could be regarded as a specific form of altruism that implies a positive attitude to other team members, and a readiness to reply to colleagues. ${ }^{(22)}$ With respect to motivation to share knowledge, empirical studies have shown that factors such as helping others (i.e. altruism) can be strong motivators of knowledge sharing behavior. ${ }^{(23)}$ Altruism is a discretionary personal attitude in which behaviors are performed without expecting any further reward and are carried out mainly to benefit others. Since helping behavior can be considered as voluntary acts performed with the intention to provide some benefit to another person, altruistic intentions appear to be intrinsically motivated as a result of a consideration for the needs of others. ${ }^{(24)}$ Several studies have found that altruistic or humanistic concern for others is a significant factor that influences knowledge sharing behaviors in virtual communities 
such as Wikipedia. ${ }^{(19,25)}$ Altruism is also regarded as one important dimension of organizational citizenship behavior (OCB). Smith et al. outlined a twodimensional framework of OCB, including altruism and generalized compliance. ${ }^{(26)}$ Several studies have suggested that OCB has a positive relationship with knowledge sharing behavior. ${ }^{(27,28)}$ For example, AlZubi examined the relationship between OCB and knowledge sharing behavior among the staffs of pharmaceutical industry companies. ${ }^{(27)}$ The literature suggested that the greater the sense of altruistic intention, the greater the behavioral intention to share knowledge.

\section{Contextual factors: team climate for innov- ation}

Studies of work-related environmental features are combined under the general heading of 'climate. ${ }^{(29)}$ Research has defined climate as a set of shared views regarding individuals' perceptions of organizational policies, practices and procedures, and has established that climate is a significant factor in shaping employee behavior. ${ }^{(30)}$ Previous studies have discussed different impacts of contextual factors on knowledge management. Van den Hooff and de Ridder argued that successful knowledge sharing needs a constructive communication climate. ${ }^{(14)}$ Zarraga and Bonache found that a high care atmosphere favors both transferring and the creating of knowledge. ${ }^{(31)}$ Bock et al. also proposed that an organizational climate conducive to innovation directly affects individuals' intentions to engage in knowledge sharing behaviors. ${ }^{(9)}$ Knowledge sharing is critical to organizational innovation because knowledge sharing leads to disseminating innovative ideas, which are considered critical to creativity and subsequent innovation. ${ }^{(32,33)}$ Therefore, a climate that is related to innovation is necessary for advancing knowledge sharing behaviors.

Although most climate research has focused on the organizational-level climate, this study takes up a team-level innovation climate to explore the relationship between team climate and knowledge sharing behavior. The theoretical rationale for focusing on the team as a climate unit is not only based on the collective responsibility members share to determine organizational outcomes, but also on the importance of the team for service quality assurance in healthcare organizations. ${ }^{(4)}$ Anderson and West argued that a team or work group is a more appropriate level of analysis to examine shared perceptions of climate in healthcare organizations because most healthcare service work is accomplished by specialized teams. ${ }^{(34)}$

In this study, we employed the well-established four-factor theory of team climate for innovation proposed by West. ${ }^{(35)}$ This theoretical model identifies four essential factors of team climate, participative safety, support for innovation, vision, and task orientation. These factors represent the salient aspects of team climate that have been covered by scholars interested in understanding individuals' tendencies toward knowledge sharing. A team climate conducive to innovation is characterized as a climate in which individuals are highly trusting of others and of the organization (e.g. support for innovation), an open climate with free-flowing information and tolerance of well-reasoned failure (e.g. participatory safety), and a climate infused with pro-social norms (e.g. vision). ${ }^{(9)}$

\section{Integrating motivational and contextual factors}

Bringing together these ideas with the arguments raised above, we posit that the team climate affects individuals' intentions to share knowledge in two ways. That is, team climate directly and indirectly (through altruistic intentions) influences knowledge sharing behavior. First, the team climate is expected to directly influence an individual's behavior of knowledge sharing. As discussed earlier, we employed the conceptual framework of West's team climate as being particularly conducive to knowledge sharing with supervisory support, support for innovation, participatory safety, and vision. Supervisory support and support for innovation reflect the shared perception that change and creativity are actively encouraged by team supervisors and organizational practices. Consequently, team members are more likely to share new and creative ideas with each other. Participative safety, which reflects a perceived sense of togetherness among team members, emphasizes open information flows and reasoned risk-taking. ${ }^{(35)}$ Participative safety, thus, can be expected to build trust between team members and to lead to free exchange of information. Finally, vision refers to shared group norms concerned with the excellence of task performance. Given a high level of climate for excellence, team members are more willing to 
engage in efforts for the sake of the team to achieve high quality performance standards. During the implementation process of any project, team members are more likely to share new strategies for problem solving and cooperate in transforming new ideas into knowledge. Consequently, vision as a social norm acts to encourage team members to collaborate and assist each other with task implementation. ${ }^{(10)}$ Thus, it seems reasonable to posit that vision will increase team members' intentions towards knowledge sharing. This leads to the first hypothesis.

H1: The greater the extent to which the team climate is perceived as being characterized by collective norms (i.e. vision and task orientation), innovativeness (i.e. support for innovation), and free-flow information exchange (i.e. participative safety), the greater will be the behavioral intention to share knowledge.

Second, prior studies examining behaviors with- in specific contextual aspects have suggested that contextual factors such as team climate influence the salience of an individual's intrinsic motivations or attitudes such as altruism..$^{(9,14,25,36)}$ For example, the organizational climate is found to exert a strong influence on the formation of intrinsic motivation such as subjective norms regarding knowledge sharing; it also directly influences an individual's intention to share knowledge. ${ }^{(9)}$ This leads to the second hypothesis.

H2: An employee's altruistic intentions mediate the relationship between the team innovation climate and knowledge sharing behavior.

This paper proposes a model (Fig. 1) that extends the initial model and states that altruistic intentions mediate the relationship between the team innovation climate and knowledge sharing behavior. This paper reports on an empirical study of the proposed model and extends the initial model to test the

\section{(A) Initial modeal}

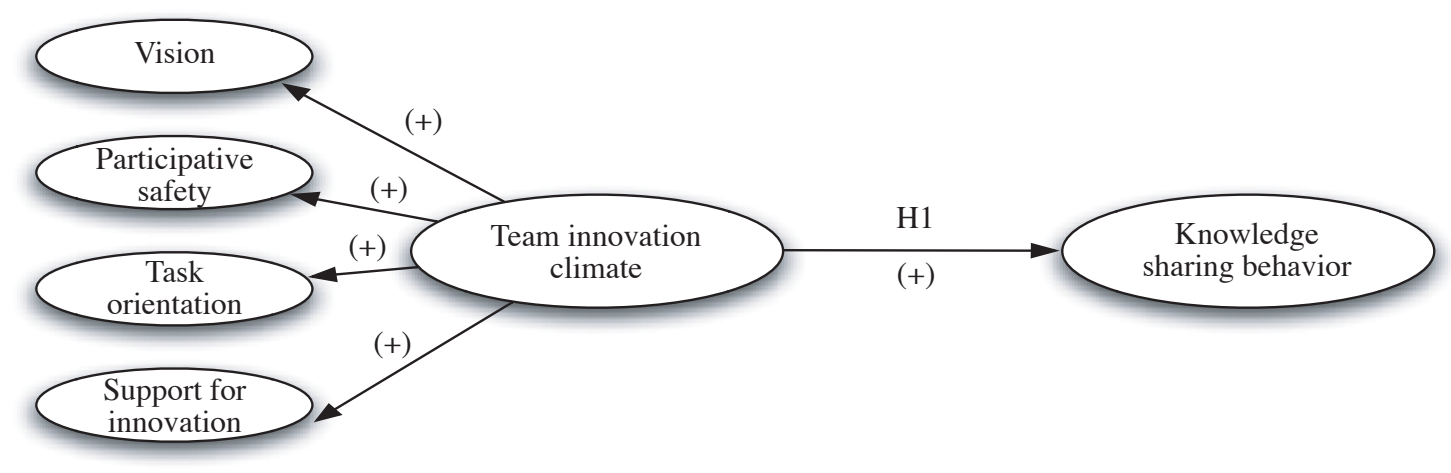

(B) Proposed model

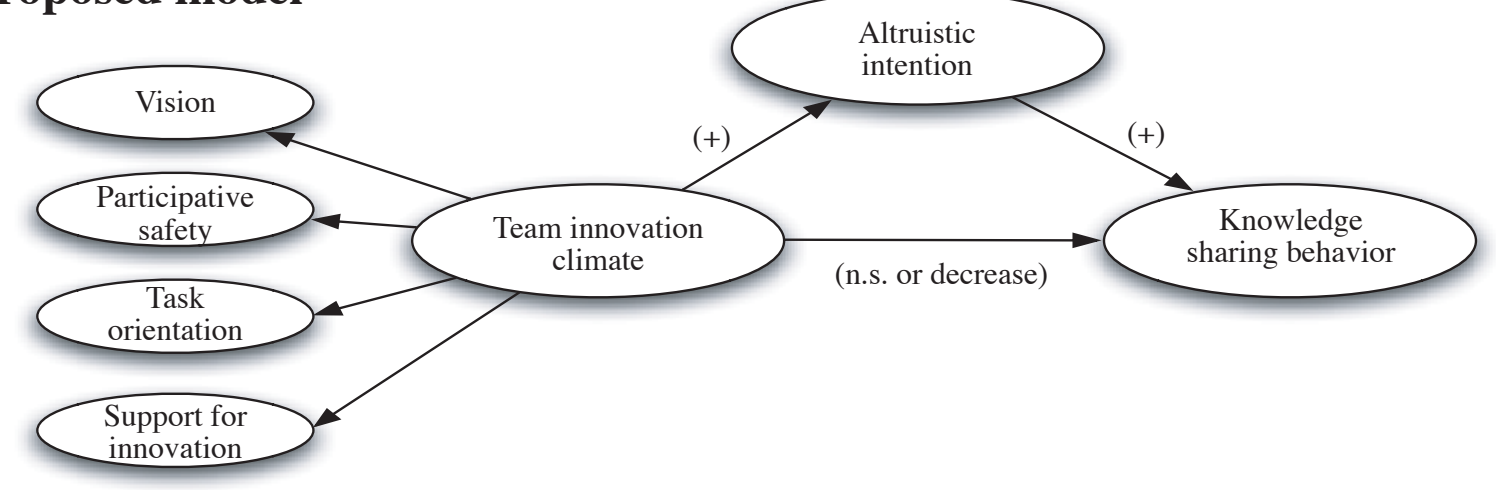

Fig. 1. Theoretical model of climate of innovation of a team and knowledge sharing behavior: (A) initial; (B) proposed model of the mediating effect of altruistic intentions. 
mediating effect of altruistic intentions.

\section{METHODS}

\section{Design and procedure}

The study used a cross-sectional questionnaire design and was conducted in a medical center in Taiwan. This questionnaire research is a staff survey, which does not require approval by the institutional review board and thus approval was not sought. The questionnaire was distributed to the team supervisor or a contact person for each team. Team members then completed the questionnaire anonymously and returned it to the supervisor or contact person, who then returned it to the investigators.

\section{Participants}

As shown in Table 1, a total of 364 questionnaires were distributed to the healthcare administrators and managers of 28 computer information and management teams. A total of 212 questionnaires with valid data were returned, representing a response rate of $58.24 \%$. Among the subjects, $73.6 \%$ had a university or higher education, and 133 $(62.7 \%)$ were men. The mean age was 38 years with a range of $20-65$ years. The mean tenure was approx-

Table 1. Respondent Characteristics

\begin{tabular}{lrc}
\hline Characteristic & Number & Percentage \\
\hline Gender & 133 & \\
$\quad$ Male & 79 & $62.7 \%$ \\
Female & & $37.3 \%$ \\
Age & 12 & \\
$\quad<25$ & 107 & $5.7 \%$ \\
$26-35$ & 69 & $50.4 \%$ \\
$36-45$ & 21 & $32.6 \%$ \\
$46-55$ & 3 & $9.9 \%$ \\
$>55$ & & $1.4 \%$ \\
Education & 33 & \\
High school & 135 & $15.6 \%$ \\
University & 44 & $63.6 \%$ \\
Graduate school & & $20.8 \%$ \\
Job tenure & & \\
$<3$ years & 68 & $* 32.1 \%$ \\
$3-6$ & 35 & $16.5 \%$ \\
$7-10$ & 41 & $19.3 \%$ \\
$11-15$ & 29 & $13.7 \%$ \\
$>15$ & 39 & $18.4 \%$ \\
\hline
\end{tabular}

imately 4 years with about a quarter having worked less than 3 years, and one-third over 10 years. The characteristics of respondents are presented in Table 1.

\section{Measures \\ Knowledge sharing behavior inventory}

This four-item measure was adapted from Cheng \& Lee. ${ }^{(37)}$ The inventory was developed along with the definition of knowledge sharing behavior by which the knowledge holder transfers the knowledge to others and helps others understand and gain knowledge. The inventory includes sharing personal knowledge, sharing learning opportunities, and encouraging others to learn. A five-point Likert-type scale was used for response options, ranging from (1) 'strongly disagree' to (5) 'strongly agree'. One example of the items is 'I always try my best to answer questions that my colleagues ask me.' The internal consistency reliability of this scale was $\alpha=$ 0.86 in this study.

\section{Team climate inventory (TCI)}

The TCI was developed to indicate the dimensions of team climate for innovation. ${ }^{(34)}$ The 38 items of the TCI are divided into the following four scales: participative safety (e.g. We have an attitude of "we are in the same boat together."), support for innovation (e.g. The assistance required to develop new ideas is easily available.), vision (e.g. How clear are you about your team objectives?), and task orientation (e.g. Do you and your colleagues monitor each other so as to maintain a higher standard of work?). The psychometric properties of the Taiwan version indicated good internal consistency. ${ }^{(38)}$ The internal consistency reliability of the four scales in this study ranged from $\alpha=0.87$ for task orientation to $\alpha=0.93$ for vision, with $\alpha=0.96$ for the whole inventory.

\section{Altruism inventory \\ This four-item scale was adapted and modified from Podsakoff, MacKenzie, Moorman and Fetter's altruism scale. ${ }^{(39)}$ It is used to assess employees' dis- cretionary intentions that affect helping another per- son with a task or problem. A 5-point Likert-type scale ranging from 1 (strongly disagrees) to 5 (strong- ly agree) was used. An example of the items is 'I would help others who have difficulties.' The inter- nal consistency reliability in this study was $\alpha=.77$.}




\section{Data analysis}

Harman's one-factor test was used to test the presence of common method variance (CMV). The lack of an apparent general factor suggests that common method variance is insignificant and unlikely to confound the interpretation of the results. The following section presents details of the study on the initial and proposed model through Structural Equation Modeling (SEM) analysis using Amos 7. A confirmatory factor analysis was first conducted to assess the measurement model, followed by examination of the structural relationship for the fit of the proposed research model. In the research model, team climate was treated as a second-order variable that was constructed using factor scores for the firstorder constructs.

To test for mediated effects we conducted two analyses: (1) Sobel's test was used to explore whether the mediator carried the influence of the predictor to the outcome variable. ${ }^{(40)}$ (2) A procedure put forward by Preacher and Hayes involving bootstrapping was also used. ${ }^{(41)}$ Bootstrapping is an alternative test to normal-theory tests of mediation, using a nonparametric method for assigning measures of accuracy to statistical estimates, whereby the standard errors are estimated using the available data.

\section{RESULTS}

As shown in Table 2, all of the indicator loadings $(\lambda)$ exceeded 0.65 , except one item in the Altruistic Intention Scale (A1). The composite reliabilities of constructs exceeded the model fit criteria, and ranged from 0.79 to 0.9 . In addition, all average variance extracts (AVEs) were greater than or equal to 0.5 , suggesting that the items captured more variance in the underlying construct than that attributable to measurement error. Convergent validity was assessed by the square root of the AVEs; all of the indicators exceeded 0.7. The overall goodness-of-fit indices of measurement model were as follows, where, $\chi^{2} / d f=2.85$, comparative fit index $(\mathrm{CFI})=$ 0.90 , normed fit index $(\mathrm{NFI})=0.85$, non-normed fit index $(\mathrm{NNFI})=0.88$, goodness-of-fit inedx $(\mathrm{GFI})=$ 0.82 , and root mean square error of approximation $($ RMSEA $)=0.09$. The results of the composite reliabilities and AVEs suggested that the general requirement of reliability and validity for the research instruments was satisfied.
Table 2. Composite Reliabilities and Convergent Validity of Measurement Models

\begin{tabular}{|c|c|c|c|c|c|}
\hline Construct and indicators & $\begin{array}{l}\text { Indicator } \\
\text { loading }\end{array}$ & & $\mathrm{CR}$ & AVE & $\begin{array}{c}\text { Square root } \\
\text { of AVE }\end{array}$ \\
\hline Knowledge sharing behavior & & & 0.86 & 0.61 & 0.78 \\
\hline KSB 1 & 0.70 & & & & \\
\hline KSB 2 & 0.83 & & & & \\
\hline KSB 3 & 0.78 & & & & \\
\hline KSB 4 & 0.80 & & & & \\
\hline Team innovation climate & & & 0.92 & 0.76 & 0.87 \\
\hline Participative safety & 0.97 & & & & \\
\hline Information sharing & & 0.84 & & & \\
\hline Safety & & 0.86 & & & \\
\hline Influence & & 0.88 & & & \\
\hline Interaction frequency & & 0.83 & & & \\
\hline Support for innovation & 0.99 & & & & \\
\hline Articulated support & & 0.88 & & & \\
\hline Enacted support & & 0.86 & & & \\
\hline Vision & 0.67 & & & & \\
\hline Clarity & & 0.81 & & & \\
\hline Perceived value & & 0.92 & & & \\
\hline Sharedness & & 0.92 & & & \\
\hline Attainability & & 0.86 & & & \\
\hline Task orientation & 0.82 & & & & \\
\hline Excellence & & 0.80 & & & \\
\hline Appraisal & & 0.72 & & & \\
\hline Ideation & & 0.87 & & & \\
\hline
\end{tabular}

\begin{tabular}{lllll} 
Altruistic intentions & & 0.79 & 0.50 & 0.71 \\
A 1 & 0.57 & & & \\
A 2 & 0.67 & & \\
A 3 & 0.76 & & \\
A 4 & 0.76 & & \\
\hline
\end{tabular}

Abbreviations: CR: composite reliability; AVE: average variance extracted. KSB: knowledge sharing behavior. Goodness-of-fit indices (N = 212) $\chi 2 / d f=3, \mathrm{CFI}=0.89, \mathrm{NFI}=0.84, \mathrm{NNFI}=0.87, \mathrm{GFI}=0.80$, RMSEA $=0.09$.

All factor loadings for the current data are significant at $p<.05$. Item numbers reflect numbering in each measurement of constructs. 
The overall fit of the observed data to the initial model (hypothesis 1) was tested, as shown in Fig. 2. The results suggested that team climate has a significant and direct effect on knowledge sharing behavior $(\beta=0.43, p<0.001)$. The path accounted for $19.1 \%$ of the variance in knowledge sharing behavior, thus supporting hypothesis 1 . To test the mediating effect of altruistic intentions on the relationship between team climate and knowledge sharing behavior, this study applied Baron and Kenny's logic. ${ }^{(40)}$ A variable functions as a mediator when it meets the following three preconditions: (a) the independent variable significantly influences the mediating variable, (b) the mediating variable significantly influences the dependent variable, and (c) when both path $a$ and $b$ are controlled, a previously significant variable between the independent and dependent variable is no longer significant. The first step was to test if the direct effect of team innovation climate on knowledge sharing behavior was the same as hypothesis 1 . The path became insignificant after introducing the mediating variable (Fig. 3), indicating that altruistic intentions have a full mediating effect on knowledge sharing behavior and explain the increased proportion of variance from $R^{2}=0.19$ to 0.64 for knowledge sharing behavior (see Figures 2 and 3 ). Mediation can also be demonstrated by bootstrapping methods. The bootstrapping test for mediation involves computing confidence intervals around the product term $\left(a^{*} b\right)$, and the mediating effect is significant if zero falls outside of the $95 \%$ interval. Following recommendations, we resampled 1000 times and applied the percentile method to create 95\% intervals. This approach provided consistent results with the mediation analyses described above. Specifically, zero fell outside the confidence interval around the indirect effects, ranging from 0.24 to 0.47 .

To summarize, the results demonstrated that altruistic intentions mediate the link between team climate and knowledge sharing behavior. Both the team innovation climate and individuals' altruistic intentions have a positive impact on knowledge sharing behavior. However, the significant effect of team

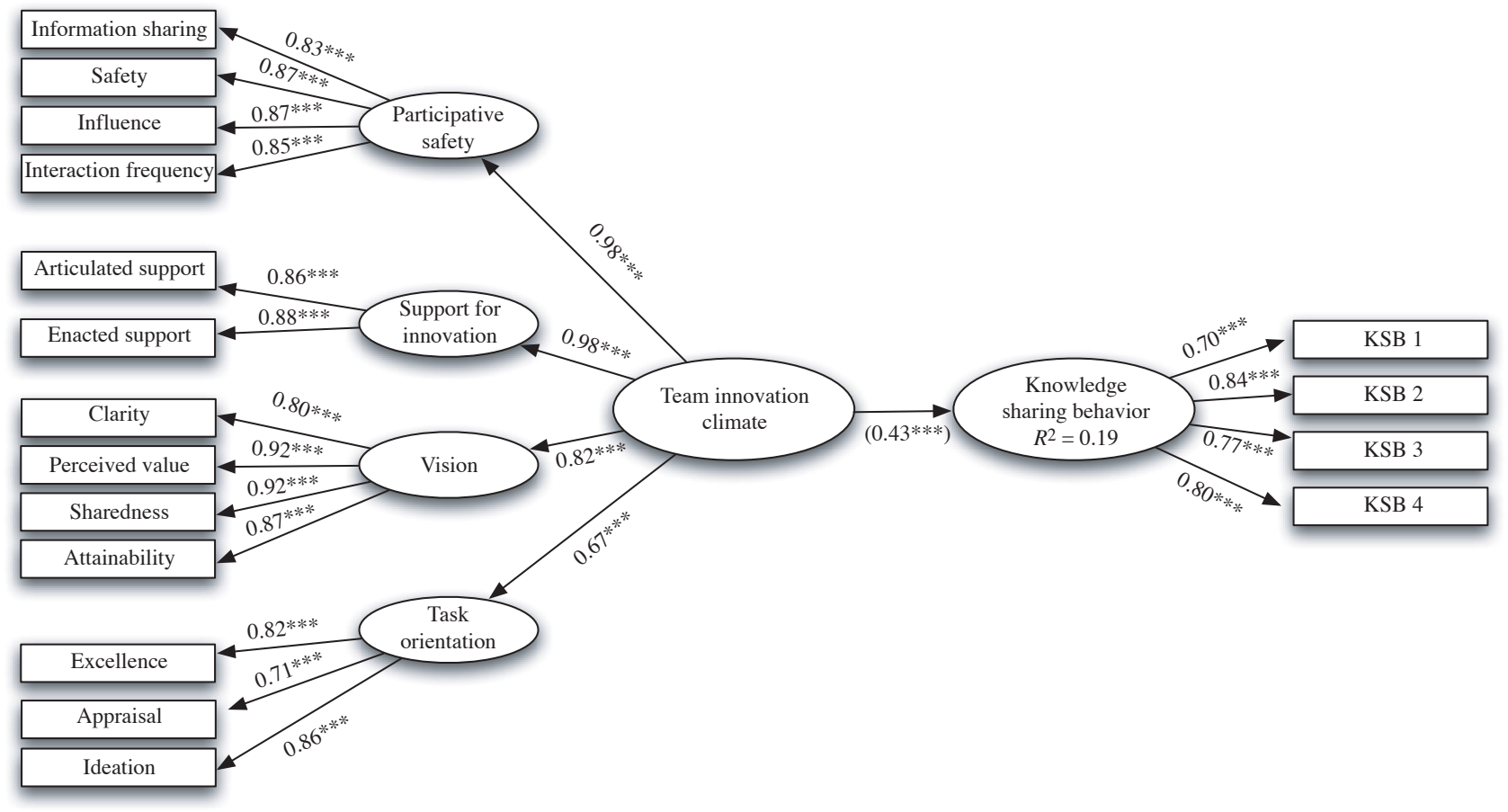

Fig. 2. Direct effects of team climate $*: p \leq 0.1 ; * *: p \leq 0.05 ; * * *: p \leq 0.01$

Goodness-of-fit indices $(\mathrm{N}=212)$

$\chi^{2} / d f=2.85, \mathrm{CFI}=0.90, \mathrm{NFI}=0.85, \mathrm{NNFI}=0.88, \mathrm{GFI}=0.82, \mathrm{RMSEA}=0.09$. 


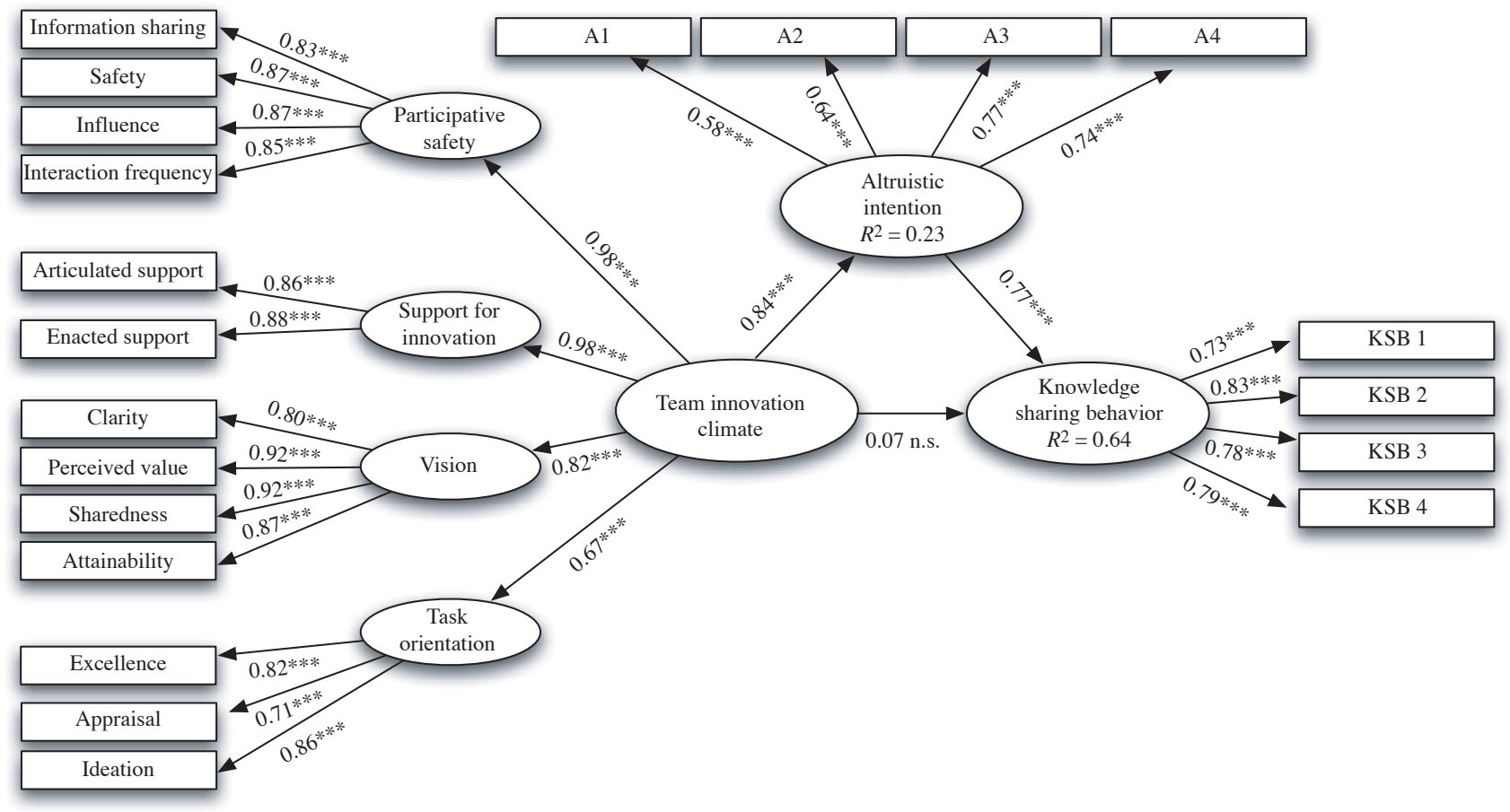

Fig. 3. Mediating effects of altruistic intentions $*: p \leq 0.1 ; * *: p \leq 0.05 ; * * *: p \leq 0.01$

Goodness-of-fit indices $(\mathrm{N}=212)$

$\chi^{2} / d f=2.16, \mathrm{CFI}=0.94, \mathrm{NFI}=0.89, \mathrm{NNFI}=0.93, \mathrm{GFI}=0.85, \mathrm{RMSEA}=0.07$.

climate on knowledge sharing behavior disappeared after introducing the mediator altruistic intentions, and in turn resulted in an increase in the proportion of variance explained. Since the results passed all tests for mediation, we concluded that altruistic intentions mediate the relationship between team innovation climate and knowledge sharing behavior.

\section{DISCUSSION}

Knowledge management in healthcare industries is naturally dynamic and largely depends on social relationships among individual workers for its creation, transference, and use. The main issue of this study was to deepen our understanding of knowledge sharing behavior by examining the theoretical relationships between key motivational and contextual factors in the context of healthcare management. Although the positive relationship between climate and knowledge sharing behavior was well received, relatively little is known about how the effects are mediated by an individual's subjective belief system such as altruistic intentions. This study empirically examined a research model and the results suggested that the positive impact of team climate on knowledge sharing is largely mediated by an individual's altruistic intentions. The current research contributes to a further understanding of knowledge management from a psychosocial perspective in a healthcare setting.

The mechanism underlying the team climate impact on knowledge sharing may be explained by ambient stimuli; ${ }^{(42)}$ that is, members' exposure as a regular part of their life in the work setting with shared group norms, climate, and the task environment. The social context heightens the individual's intention to engage in knowledge sharing behavior. The finding indicated that creating a team climate conduct to innovation (operationalized here as vision, participatory safety, support for innovation, and task orientation) could be viewed as a beneficial means of promoting and encouraging knowledge sharing behavior.

We found that an intrinsic motivational factor, 
altruistic intentions, exerted a strong influence on knowledge sharing behavior. This is consistent with previous results of studies which showed that altruism is one of the strongest motivators among psychological factors. ${ }^{(9,19,25)}$ The team innovation climate intensifies the salience of the subjective belief system that governs the willingness of individuals to present knowledge sharing behavior. That is, the more employees perceive a climate characterized by participative safety, support for innovation, clear team vision and high task orientation, the more they will use their altruistic intentions to share knowledge with others. Thus, knowledge management strategies need to account for individual's altruistic intentions in knowledge sharing.

Based on our findings, we propose the following suggestions to those desiring to encourage knowledge sharing within their teams. Fostering a highly innovation-oriented work context is likely to nurture individuals' intentions, which are apparently important in driving knowledge sharing behavior. In a practical sense, knowledge sharing behavior cannot be forced, but only encouraged and facilitated. Furthermore, changing people's behavior is the greatest challenge for team members' knowledge sharing behavior. As knowledge sharing is important for healthcare organizations, managers need to recognize the importance of building an innovative climate to effectively exert influence on employees' altruistic intentions, which in turn will increase knowledge sharing behavior.

Despite the tendency to emphasize the role of information technology in knowledge sharing, a growing number of studies have pointed out the importance of the holistic view, which recognizes the interplay between social and technical factors. A well-designed knowledge management system (KMS) is essential for knowledge management, but it is not likely to be the only key player for enhancing knowledge sharing. Employees share knowledge more willingly when motivated. The motivation could be either intrinsic or extrinsic. Results of previous research suggested that extrinsic rewards may be effective in the initial stage of accumulating knowledge, but the effects may become weaker. ${ }^{(15)}$ Our results confirm that intrinsic rewards such as altruistic intentions can facilitate knowledge sharing, which would thus favor the shift from extrinsic rewards to intrinsic rewards as knowledge manage- ment practices become mature. For better practice of knowledge management, it is therefore suggested that at the beginning an organization needs to implement a well-designed KMS infrastructure for knowledge sharing. Following implementation, an extrinsic rewards system may be established to boost the occurrence of knowledge sharing behavior. Afterwards, knowledge managers need to shift their focus to increase intrinsic motivators such as employees' altruistic intentions.

The current study had some limitations that also indicate the direction for future research. First, data collection was limited to a management team in a healthcare organization. The findings should be tested further using samples from clinical teams such as physicians or nurses, where knowledge sharing is more profound and valuable for healthcare services. ${ }^{(43,44)}$ Second, we focused on only a selected set of variables to represent motivational and contextual factors. As reviewed above, studies have shown that knowledge sharing can be induced or mediated by many other motivational factors. Therefore, future studies may integrate those variables to gain a more comprehensive understanding of the psychosocial enablers behind knowledge sharing. Third, this study's findings were based on a cross-sectional survey and correlational analyses. Although the SEM technique was employed to test the research model, the posited causal relationships could only be inferred rather than proven. In addition, a self-reported questionnaire may raise the possibility of common method biases. Although precautions were taken to minimize the possibility of CMV in this study, there are other factors (e.g. organizational culture or rewarding systems for knowledge sharing) that may have inflated the strength of the relationship among these constructs. Nonetheless, future studies may adopt an experimental design or longitudinal studies to further test the causal relationships implied in this study.

In summary, the current study contributes to the literature concerning the psychosocial perspective of knowledge sharing behaviors. A person's knowledge sharing behavior is determined by altruistic intentions to perform the behavior and altruistic intentions are influenced by the person's perception of a team innovation climate. Contrary to the assumption that knowledge management is mainly a technical problem easily solved by introducing an efficient infor- 
mation system, this study highlights the importance of the psychosocial variables and individual propensity to understand the dynamics of knowledge sharing behavior.

\section{REFERENCES}

1. Caldwell BS. Knowledge sharing and expertise coordination of event response in organizations. Appl Ergon 2008;39:427-38.

2. Currie G, Finn R, Martin G. Spanning boundaries in pursuit of effective knowledge sharing within networks in the NHS. J Health Organ Manag 2007;21:406-17.

3. Graham JM, Brinson M, Magtibay LV, Regan B, Lazar EJ. Virtual patient safety rounds: one hospital system's approach to sharing knowledge. J Healthc Qual 2009;31:48-52.

4. Rangachari P. Knowledge sharing networks related to hospital quality measurement and reporting. Health Care Manage Rev 2008;33:253-63.

5. Lloria B. A review of the main approaches to knowledge management. Knowl Manage Res Pract 2008;6:77-89.

6. Gourlay S. Knowledge management and HRD. Human Resource Devel Int 2001;4:27-46.

7. Jarvenpaa SL, Staples DS. Exploring perceptions of organizational ownership of information and expertise. $J$ Manage Inform Syst 2001;18:151-83.

8. Nonaka I. A dynamic theory of organizational knowledge creation. Organ Sci 1994;5:14-37.

9. Bock G, Zmud RW, Kim Y, Lee J. Behavioral intention formation in knowledge sharing: examining the role of extrinsic motivators, social-psychological forces, and organizational climate. MIS Quart 2005;29:87-112.

10. McEvily SK, Das S, McCabe K. Avoiding competence substitution through knowledge sharing. Acad Manage Rev 2000;25:294-311.

11. Alavi M, Leidner DE. Review: knowledge managment and knowledge management systems: Conceptual foundations and research issues. MIS Quart 2001;25:107-32.

12. Davenport TH, Prusak L. Working Knowledge. Boston MA: Harvard Business School Press, 1998.

13. Hendriks P. Why Share Knowledge? The influence of ICT on the motivation for knowledge sharing. Knowl Process Manage 1999;6:91-100.

14. Van den Hooff B, Ridder JA. Knowledge sharing in context: the influence of organizational commitment, communication climate and $\mathrm{CMC}$ use on knowledge sharing. J Knowl Manage 2004;8:117-30.

15. Choi SY, Kang YS, Lee H. The effects of socio-technical enablers on knowledge sharing: an exploratory examination. J Inform Sci 2008;34:742-54.

16. Bock G, Kim Y. Breaking the myths of rewards: An exploratory study of attitudes about knowledge sharing.
Inf Resour Manage J 2002;15:14-21.

17. Kankanhalli A, Tan BCY, Wei KK. Contributing knowledge to electronic repositories: an empirical investigation. Manage Inform Syst Quart 2005;29:113-43.

18. McLure-Wasko M, Faraj S. Why should I share? Examining social capital and knowledge contribution in electronic networks of practice. Manage Inform Syst Quart 2005;29:4.

19. Nov O. What motivates Wikipedians? Commun ACM 2007;50:60-4.

20. Ajzen I, Fishbein M. Understanding attitudes and predicting social behavior: NY: Prentice-Hall, 1980.

21. Von Krogh G. Care in knowledge creation. Calif Manage Rev 1998;40:133-53.

22. De Vries RE, Den Hooff B, De Ridder JA. Explaining knowledge sharing: The role of team communication styles, job satisfaction, and performance beliefs. Commun Res 2006;33:115-35.

23. Lin H. Impact of organizational support on organizational intention to facilitate knowledge sharing. Knowl Manage Res 2006;4:26-35.

24. Mergel I, Lazer D. Lending a helping hand: voluntary engagement in knowledge sharing. Int $\mathrm{J}$ Learn Change 2008;3:5-22.

25. Cho H, Chen M, Chung S. Testing an integrative theoretical model of knowledge-sharing behavior in the context of Wikipedia. J Am Soc Sci Technol 2010;61:1198-212.

26. Smith C, Organ DW, Near JP. Organizational citizenship behavior: its nature and antecedents. J Appl Psychol 1983;68:653

27. Al-Zubi HA. Organizational citizenship behavior and impacts on knowledge sSharing: an empirical study. Int Business Res 2011;4:221-7.

28. Sun LY, Aryee S, Law KS. High-performance human resource practices, citizenship behavior, and organizational performance: A relational perspective. Acad Manage J Archive 2007;50:558-77.

29. Patterson MG, Warr P, West M. Organizational climate and company productivity: The role of employee affect and employee level. J Occup Organ Psych 2004;77:193216.

30. Schneider B, Reichers AE. On the etiology of climates. Pers Psychol 1983;36:19-39.

31. Zarraga $\mathrm{C}$, Bonache $\mathrm{J}$. The impact of team atmosphere on knowledge outcomes in self-managed teams. Organ Stud 2005;26:661-81.

32. Darroch J, McNaughton R. Examining the link between knowledge management practices and types of innovation. J Intellect Cap 2002;3:210-22.

33. Earl M. Knowledge management strategies: toward a taxonomy. J Manage Inform Syst 2001;18:215-33.

34. Anderson NR, West MA. Measuring climate for work group innovation: development and validation of the team climate inventory. J Organ Behav 1998;19:235-58.

35. West MA. The social psychology of innovation in groups. 
In: West MA, Farr JL, eds. Innovation and Creativity at Work: Psychological and Organizational Strategies. Chichester: Wiley, 1990;309-33.

36. Ostroff C. The effects of climate and personal influences on individual behavior and attitudes in organizations. Organ Behav Hum Dec 1993;56:56-90.

37. Cheng J, Lee S. The relationship between organizational justice, trust and knolwedge sharing behavior (in Chinese). J Hum Resour Manage 2001;1:69-93.

38. Tseng HM, Liu FC, West MA. The team climate inventory (TCI): a psychometric test on a Taiwanese sample of work groups. Small Gr Res 2009;40:465-82.

39. Podsakoff PM, MacKenzie SB, Moorman RH, Fetter R. Transformational leader behaviors and their effects on followers' trust in leader, satisfaction, and organizational citizenship behaviors. Leadership Quart 1990;1:107-42.

40. Baron RM, Kenny DA. The moderator-mediator variable distinction in social psychological research: conceptual, strategic, and statistical considerations. J Pers Soc Psychol 1986;51:1173-82.

41. Preacher KJ, Rucker DD, Hayes AF. Addressing moderated mediation hypotheses: theory, methods, and prescriptions. Multivar Behav Res 2007;42:185-227.

42. Hackman JR. Group influences on individuals in organizations. In: Dunnette MD, Hough LM, eds. Handbook of Industrial \& Organizational Psychology. Palo Alto, CA: Consulting Psychologists Press, 1992.

43. Leiter MP, Jackson NJ, Shaughnessy K. Contrasting burnout, turnover intention, control, value congruence and knowledge sharing between Baby Boomers and Generation X. J Nurs Manag 2009;17:100-9.

44. Ryu S, Ho SH, Han I. Knowledge sharing behavior of physicians in hospitals. Expert Syst Appl 2003;25:113-22. 


\title{
醫務管理團豚的創新氣候與知識分享之探討一 利他意圖之中介效果
}

\author{
劉鳳娟 鄭凱玲 ${ }^{2}$ 趙銘崇 ${ }^{1}$ 曾旭民1
}

背 景: 本研究主要探討在醫務管理情境中, 醫務管理團隊的團隊氣候對團員知識分享行爲 的影響, 並探討個別團員利他意圖的中介效果。

方 法: 運用問卷調查法調查台灣一家醫學中心的管理團隊之成員, 共得 212 筆行政或管理 成員的有效資料。團隊氣候量表用來測量團隊與創新有關的氣候, 包含四個次量 表：參與安全、創新支持、願景、工作導向。資料分析主要運用結構方程式模型來 探討相關變項之間的關係。

結 果: 與創新有關的團隊氣候對知識分享行爲有顯著的正向效果, 同時團隊成員個別的利 他意圖数於團隊氣候和知識分享行爲之間的關係具有完全的中介效果。

結 論：本研究結果對知識管理以人爲主的理論有所蛽獻。其中個別成員的利他意圖所扮演 的中介角色對醫務管理者在推展知識分享相關管理作爲時具有實務的應用價值。

(長庚醫誌 2012;35:408-19)

關鍵詞：知識分享，團隊創新氣候，利他意圖，醫務管理 